\title{
The Poetic City
}

\section{A Literary Field for Multicultural Studies Depictions: Greece as a Case Study}

\author{
Triantafyllos H. Kotopoulos \\ Greek \& Children Literature, Department of Early Childhood Education \\ University of Western Macedonia, Florin, Greece \\ Email: tkotopou@gmail.com
}

Received: January 22, 2012

Accepted: April 26, $2012 \quad$ Published: June 1, 2012

doi:10.5539/res.v4n2p188

URL: http://dx.doi.org/10.5539/res.v4n2p188

\begin{abstract}
This paper focuses on the study of the urban space as a multiculturalism field in illustrated children's books that were in circulation in Greece after 2000. We examined the model of the immigrant and the "different", the "other", inside the fictional, literary city as an eminent symbol that emerges from socio-political circumstances and its various, selective, fragmentary and conditioned by the author's point of veiw representations. Also we investigated the extent to which iconographic and textual representations of the "other" in urban space constitute either a "neutral" and "objective" imprinting of social reality, or serve towards reproducing sovereign ideologies.
\end{abstract}

Keywords: Literature, City, Multicultural, Illustrated books, Other

\section{Introduction}

Exploration of "city-space" from a humanistic perspective requires from us to overcome an antithesis. We must dissociate the actual urban space, with its geometric characteristics, from the poetic city space and its literary landscapes. The latter is not simply an order of material things. It also stresses their qualitative relationship with us. The city, in any case, determined diachronically the cultural identity of world. From the ancient city - state we passed to medieval state, which it is structured on the sovereignty of church and guilds, and to the city of Renaissance - with culture and trade to undertake the formative part - then in the industrialized era, with the high concern on profit, to end in post - industrialized era, multifocal and acentric (Pike, 1981 p. xii - Preface). This totalitarian city characterized by technological sufficiency, has been exceptionally corruptible, when it comes to social sufficiency, and reluctant to ensure social justice for its citizens. More problems appear emphatically, such as control of information, manipulation of citizens, restriction of individual liberties etc.

Eighteenth century is characterized/marked by a modification in the representation of urban space in literature. A former invariable adherence on space turned into a fragmentary, constantly shifting, subjective kaleidoscope. Until twentieth century, city had been represented in novels precisely as a place that was becoming gradually less spatial and more human (Augustine, 1991 pp. 73-74). For example, Dostoyevsky’s Moscow or Dickens' London symbolise and condense the growth of the industrial and commercial culture, through which the writer depicts man's downgrading, seediness, inhumanity and unfairness to fellow men. In literary textual spaces of 20th century, part of society's cultural system, the modernism, concurred with the presentation of urban space, the urbanism.

The City, the most extended of man-made spaces, has been an important force for social change, as it reveals and reinforces social diversifications (Hall, 2002), while opressing the outcasts of slums and streets.

The City, the most complete and complicated spatial factor of adaptation ever created, had been rather adultcentric in its conception and function. Nevertheless, in spite of its former limitations from production and distribution of labour, city became a agent of social change in post-industrial capitalism. In a world characterised by constand collusions of multiculturalism with monoculturalism, city constitutes the main field of a multicated 
process. But, is this change reflected in cities of literature? It should be mentioned that, for the first time in human history, children of twentieth century were detached from economic life and were placed in a new symbolic environment made of books, clothes, schools and toys. By "acting as interpreters of adult activities" (Schwartzman, 1979 p. 25), twentieth century's children were involved into a complex, yet autonomous children's culture, which, though produced by adults, was addressed to (supposed) children's, needs and views.

\section{The City in Literature}

All kinds of space involve subtexts that fuction as transitional objects and expressing society's evolutions and our investments upon them. Urban space, as a diachronic social organism, houses and transforms human activity, while, simultaneously, acquires meaningfulness through collective activities. From the city - state of the distant past (Athens $5^{\text {th }}$ century B.C.) to the modern safe city, space has been considered synonymous with culture and determined diachronically the cultural identity of the social world. The dialogue of Socrates with Phaedrus is indicative of the significance of city life. When the latter criticizes his teacher as bigoted with the town market//I -and deprived of locomotion outside Athens-, Socrates answers conclusively: 'because I love to learn all the time', meaning that one can be taught, rather exclusively, by people living in the city (Plato, Phaedrus $230 \mathrm{~d}$ ).

The study of representations and their contribution to the comprehension of the social operations has proven itself an important field for social and anthropological research (Breadsley, 1989) with regard to space. Apart from serving other symbolic forms of expression and representation, literature has always played a vital part in the reflection upon spatial matters. Literature, as a way to represent the world through writing, does not only portray the world. It also constitutes a world, and hence its powerful pedagogical function. Besides, literature can reproduce, to a significant extent, a desirable world (mostly to the hegemonic forces). As it is well known from the sociology of spatial space (Hall, 2002), people tend to "understand" and "exercise their everyday life" in city space, using some key elements which also act as identification figures. It is, therefore, natural for artists to draw "the most characteristic scenes and places" of a city in children's books.

Our paper focuses on the study of urban space as a field of the imprinting of multiculturalism in illustrated children's books that were in circulation in Greece after 2000. More specifically, we examined various representations of the "young other": the immigrant and the "different" inside the fictional, literary city. We investigated the extent to which iconographic and textual representations of the "other" in urban space constitute either a "neutral" and "objective" imprinting of social reality, or serve towards reproducing sovereign ideologies. Undoubtedly, this representation is selective, fragmentary, and conditioned by the author's point of view. We thus investigated the model of the "other", that is an eminent symbol that emerges from socio-political circumstances. The unavailability of explanatory and narrating iconography attributes masterfully to the developed reflection, according to which the picture sometimes extends notionally the text and, sometimes, attributes words of it. Illustration types are elected as means of creative expression or static report.

For the purposes' of the study, 22 illustrated children's books (written and illustrated by Greek artists and published after 2000) were selected and analyzed. Proportional/Relevant publications were recorded mainly after the crucial decade 1990-2000, when a huge number of immigrants came to Greece. In the field of Children's Literature the social impact of immigration was rather straightforwardly impressed in fiction. A little later, there appeared illustrative and textual books with double code of narration, addressed to younger kids. In "illustrated books", pictures usually translate or impress indicatively central patterns of the text (Giannikopoulou, 2006; Sivropoulou, 2004). In a "picture book" we ascertain collaboration between the illustrative and the textual. In this category we come across exceptional books where picture plays a decisive and direct role, annihilating or limiting the role of language merely in titles and complementary captions. A weak presence of illustration addresses a book to older children, while copious illustration refers to younger children, with undeveloped reading abilities. In this occasion younger children express themselves mostly through illustrations, namely they direct emotions and thoughts through pictures.

\section{Multicultural vs Intercultural}

Opposite to diachronic identity of urban space, Multiculturalism, marked by rapid changes in communication and socio-economic life, transformed puzzling individuals and wider demographic groups, rendering them seekers of new notional relationships in post-national states. Terms such as "multiculturalism" and "interculturalism" are often confused and used interchangeably. According to the director of Cross-cultural Education Center-University of London, professor Gundara (1986), modern societies are characterized by their multiculturalism. That is to say, they are inhabited by diverse populations, whereas interculturalism refers to interaction and reciprocal collaboration these populations should be after. "Multiculturalism" is mainly used to describe a definite social reality and its developmental process, while "interculturalism" denotes a dialectic 
relation, a dynamic process of interaction, mutual recognition and collaboration among individuals of various national groups (Markou, 1997a:238). "Multicultural" should characterise a directly perceptible social situation, while its undertaken processes are influenced by the marginalization of certain cultural groups. On the contrary, "interculturalism" should characterize pedagogic, sociocultural perceptions and programmatic objectives.

The fluidity and diversity of the terms "multiculturalism" and "interculturalism" hinder the development of a methodological way to approach them, in order to deal with questions of immigration and globalization. Disciplines such as Cross-cultural Education, Cross-cultural Theology, Cross-cultural Philosophy, Cross-cultural Sociology, Cross-cultural Hermeneutics etc. have recently flourished in this field. Consequently, an interdisciplinary approach to the term has been imposed, -though much of its appeal rests on the aforementioned conceptual variety- in order to offer convincing answers to contemporary social, political and economic developments. On the other hand, as has been claimed, multicultural literature focuses on colored people, religious minorities, local cultures, disabled, elderly etc. (Violet Harris in Norton 2007:531). The urban space in the Modern Greek Children's Literature offers the possibility to review vital terms, such as variation and difference, which offer young readers the capability to build up new and accomplished socio-cultural identities.

\section{Analysis}

Two groups of illustrated books (i.e. books where the picture usually translates or impresses indicatively the central topics or patterns of the text, Giannikopoulou A. 2006 and Sivropoulou R. 2004)) and picture books (where the chief element is a balanced collaboration between picture and textual-linguistic code, in a context that allows the emphasis in either sides) were formed upon the image of young "other" and his/her uniqueness. In the former, there were seven (7) stories where protagonists are animals with anthropomorphic behavior and realistic features (rooster-5, worm-14, little fich-15, donkey-13, centipede-22, bear - cub-10, ant-17) (Note 1). Along animals, personified natural elements (little star-6, flower-8, chocolate-7, milk-4), and portrayed to hold leading parts. Protagonists belong to the group of weak people who, when holding leading parts (in both illustration and text) might impede easy identifications. Nevertheless, they might allow an easier approach and familiarization by younger readers. In fact, young readers' animistic thinking enables a faster process of identification with natural elements, over which he/she believes that he/she can exert an indirect control. Eventually, and according to the story's outcome, the reader actually shares the symbolic victory of the young animal or natural element, upon his/her enemies. In the second group, characters are usually primary school children whose behavior, reactions and manner of speaking, occur in the context of school -though this is usually implied and not openly stated. The setting is usually a school, or an urban square, unlike previous stories where settings appear inaccessible to man-elements or natural elements- and create settings inaccessible to men, almost unreal and irrational (the seabed, the sky etc).

The initial difficulty of Greek students to accept and understand the particularities and choices of the "other" is repeated rather regularly. Nevertheless, this attitude changes through a progressive acquaintance, contact, co-existence and communication. Many younger characters confront problems of malformation, health and disability $(16,18,19,20$, and 21). In two books we can get information about children's life in poorer African countries $(12,3)$, while, in one book, space appears to be rather symbolic and not specified geographically (9). The various versions of the young "other" are depicted either in forms of very specific activities or in those of well-defined characters. In the beginning the 'other' is usually accepted or rejected by the class, while he/she coexist, communicate with teacher, and participate in schoolyard games during brakes. Sociologists like Kline (1993) argued for the existence of a «shared sense of a children's culture», challenged by «a more decisive imagery of miniaturized consumption tribes» (p. 288). These cultures followed the decline of traditional family or friendship (not able «to pay a visit» as often as we could!) and the prevalence of working values.

Essential information regarding the social system where immigrants were hosted is exclusively recorded in the book of A. Varela Give the Love. As we can understand, Greek authorities were unprepared for such a reception. This is clearly depicted in those children's books whose main concern is to stress the elements of difference which, nevertheless, gradually disappear, thus bringing everything to a happy end of integration. It is evident that an optimistic conception regarding tolerance and acceptance of the young "other" in Greek education and society in general is displayed. Traces of integration are detected only in the Good morning friend an in Give the Love. In any case everything seems to halt with the acceptance of the little "other" within the framework of friendship and game. Characteristic examples of that development are seen in Give the Love where we can faintly see the first signs of a multicultural school and a respective Greek multicultural society. Regardless of this development, the dilemma of integration or assimilation is neither clearly posed nor answered in any way, regardless of what usually occurs in a 
In books where characters are animals or natural elements the narration, both in the text and the illustration, is in third-person narrative with an omniscient point of view. The book of L. Varvarousi A little fish that didn't know how to swim is the only exception. A heterodiegetic textual narrator with omniscient point of view recounts in a completely neutral manner the actions and the words of the others. At the same time, a respective illustrative narrator depicts almost the same story with lines, shapes and colors. It seems that narrative techniques of this kind befit to some extend the young children's psychology and may possibly respond to skills and experiences of young readers. The narrator's stability and certainty cause fewer problems regarding both comprehension and the following of story-plot. More specifically, the stability in the flow of the narration, as well as the narrator's absolute certainty are in tune with children's special features. Besides, the popular folk story-telling has chosen these narrative techniques for several years with the exception of the last 50 years.

In books where a typical little immigrant is the protagonist (1 to 9), the portrayals and the descriptions of his little or great adventures are filtered either by the first-person narration //or by/// the third-person narration with omniscient point of view. This procedure influences the illustrative narrator either completely or partially. The amalgam of created peculiar situations or the disagreement between the two narrators can lead to various possible results that could be seen in the books My name is Promise, Give the Love and Good morning friend .In the first book, specifically, the illustrative narrator appears to be talking in the $3^{\text {rd }}$ person with omniscient point of view, despite the fact that the textual narrator appears to be talking in the first person and is characterized by inner focusing. In a characteristic page of the book My name is Promise (picture 7) what is depicted is the group of the heroin's classmates that follows her look. According to the textual narrator it is the heroine who is looking and it is the look of Promise that is being depicted. Yet, in another picture (8), we can see a mixed situation remindful of techniques borrowed from comics (Martinidis, 1990). On the one side, the textual narrator (Promise) recounts on inner focusing, while, on the other, the illustrative narrator selects and recounts events without any focusing. This, however, creates, at the same time, an illusion of inner focusing. The illustrative portrayal of the father starts from a base and follows an onward direction, just as little Promise would have seen it from below. In the book Give the Love the textual, omniscient third-person narrator agrees with the illustrative narrator (picture 9), while, in certain cases, a mixed situation takes place. We see the simultaneous display of the looks of the hero and the third-person narrator, since the narrator himself is depicted in the picture (picture 10). In the book Good morning friend what is considered significant is that the narration is in first-person narrative and that the inner focusing in the text is accompanied by an inner focusing on illustration. That means that the point of view of the little child is always obvious in illustration. In this way reading becomes safer and rather easier for the young reader who views illustration as a significant assistant in the comprehension of the meaning. Impressive are the cases (picture 11) where the depiction of the look of the young boy-narrator in the portrayal of the figurative reality is thought to be characteristic. Specifically in these pictures we can see the use of the techniques borrowed from comics. We can see that something similar, but at a lower degree, is happening in picture 9 where the height from which the inside of the room is viewed is identified with the look of the little hero-narrator.

Illustrators are invited to select the most characteristic scenes of a city and portray them, while, inside the text, descriptions of corresponding themes are extended. They insist mainly in the structured environment of the city $(1,2,4,6,7,10,11,12,13,14,15,16,17,19,20,21,22)$ and in the social $(1,2,3,4,5,8,9,10,11,12,13,14$, $15,16,17,18,19,20,21,22)$. Less are the reports in natural environment $(8,12,16,22)$, while we did not meet representation of city's great historical moments. Note here that in illustrated books and picture books (Kotopoulos and Karakitsios, 2007): $a$. In the depiction of natural environment of the city the liquid element (water) has a positive function, while it constitutes, for the characters, the shelter where they could retrieve $b$. The presence of the "other" in urban space like a member of national group or social minority is recorded in the iconographic imprinting of social environment. In texts with anthropomorphous representations and animistic heroes, urban space is depicted both symbolically and realistically; while in texts where characters are children, realistic representation seems to prevail. For example Blushy the red star (6) wanders in the avenues of Galaxy, crosses the spatial road of "Comets - Meteorites" which leads to a deserted lane named "Starlight". The illustrator attempts to portray this symbolic speech in two consecutive pages where naturally colored stars watch the stranger walking in an enormous stellar avenue marked with the sign "Avenue of Galaxy". Symbolization of noisy urban space also appears in the 8th book where the protagonist is a multicolored flower named Arlekinos. The plain with the flower and the bee is organized in two consecutive depictions remindful of the permanent big city's movement; while the stationary house in the bottom of left page winger declares the illustrator's intentions. In texts dealing with the diversity of the immigrant, the social environment of urban space plays the decisive part in his/her progressive incorporation. Since school is mainly undertaking the incorporating part, the illustrators hasten to represent school rooms $(1,2,3,4,5,11,15,18)$ or courtyards $(2,3,11)$, where the young immigrant is 
initially marginalized, but progressively through teacher's interventions, daily contact with peers and, primarily, through game's "magical" qualities, he is eventually adapted into the school's community. The positive functions of urban space do not run out in the mere reception of the little immigrant. Illustrators often contradistinguish the Greek city with the place where the hero / heroine used to live. In the cover of My name is Promise (1) the young heroine is portrayed in the middle of the page having on her left a background of neoclassic buildings and modern skyscrapers with a highway, while on her right we can discern a giraffe, declarative of the African continent and Promise's native country, Nigeria, (distinguished for its excessive heat and lack of water and food). In texts where young heroes face health or disability problems the city is impressed in a variety of manners. When the protagonist (a teddy bear named "Happy") suffers from leukemia, the positive role of the city is depicted through the health system and the hospital -with all its personnel- where cases are treated (10). In the history (17) of little Doop (an ant) city is represented with its negative and positive elements. Drugs are symbolically portrayed with the inhalation of black poppy pollen. The hero however, manages to save his life through participating in athletic games (depiction of stages and various sports). In another text (18) the sports and the power of love give, once again, the solution, relieving the dwarf hero inside a depicted urban environment. Gyms and the Special Olympic Games dominate the illustration of "Thomas" (19), where the young hero is mentally defective. Besides, the archetype of the luminous city is connoted by the depiction of an airport. . In Phoebus... and the other Phoebus (20) the joy of the "other Phoebus" is depicted during his exercise in gym. In Sakis the Centipede (22 the depiction of the busy city of vermins with lots of streets and blocks of flats, while theater and buildings pictures is particularly descriptive.

\section{Conclusions}

1. The presence of urban space has been proven decisive for both plot and outcome of the diversity of the characters.

2. In the majority of cases the problems that young immigrants encounter inside the Greek educational system are impressed almost stereotypically. By offering the chances of more intense peer-influences, school becomes the ultimate place where children meet and understand the world; the fundamental place of coexistence with others in an isolated adult postmodern world.

3. The absence of a clear cut schedule regarding incorporation or co-existence of the young "other" in Greek society can be easily witnessed in children's novels published in the previous decade, 1990-2000. During the last decade (2000-2010) the abundant presence of pictures shows, rather clearly, the shift from denial and dissimilitude to a universal acceptance and assimilation, since immigrant students start to increasingly resample their Greek schoolmates.

4. When linguistic and illustrative text co-exist and collaborate, the book reader becomes a viewer of the illustration in the sense that he has the narration of the story spread in front of his eyes both in pictures and words, that is in two different codes. The fact that the textual and illustrative narrator as well as the inner focusing and the omniscient point of view are in conflict, not only distorts the story, but also acts towards impending its flow. We can ascertain the prevalence of official views which are usually conservative positions expressed by the state. In addition to the above, the difficult points of the story presented in a textual form are decomposed and deconstructed, instead of being strengthened as far as information is concerned.

\section{References}

Ampatzopoulou, F. (2001). Imagologie and its aims. Diavazo, 415, 90-96.

Augustine, J. (1991). From topos to anthropoid: the city as character in twentieth-century texts. In Caws, M. A. (Eds.), City Images: Perspectives from literature, philosophy and film (pp. 73-86). New York: Routledge Press.

Bachelard, G. (1982). The poetics of Space. Athens: Hatzinikoli Press.

Berelson, B. R. (1971). Content analysis in communication research. New York: Hafner.

Breadsley, M. (1989). The History of Aesthetic Ideas. Athens: Nefeli.

Cunningham, H. (1991). The Children of the Poor: Representations of Childhood since the Seventeenth Century. Oxford: Blackwell.

Jenks, C. (1996). Key Ideas: Childhood. London: Routledge.

Hall, P. (2002). Cities of Tomorrow: An Intellectual History of Urban Planning and Design in the Twentieth Century. New York: Blackwell. 
Genette, G. (1972). Figures III. Paris: Seuil.

Genette, G. (1983). Nouveau discours du récit. Paris: Seuil.

Giannikopoulou, A. (2006). Focusing in the different focuses of the illustrative children's books. In Papadonakis, G. (Eds.), Narrator's faces and facades in Greek Children Literature during the last thirty years (pp. 59-81). Athens: Patakis.

Gundara, J. (1986). Education for a multicultural society. In Gundara, J. (Eds.), Racism, diversity and education (pp. 4-27). London: Hodder \& Stoughton.

Guyard, M. F. (1988). Literary Comparative-History and Criticism. Athens: Zacharopoulos.

Hunt, P. (1991). Criticism, Theory, and Children's Literature. Oxford: Basil Blackwell.

Kapsomenos, E. (2004). Narratologie. Athens: Patakis Press.

Kotopoulos, H. T., \& Karakitsios, A. (2007). The urban landscape in Children's literature. In Richardson, A., \& Wyness, M. (Eds.), Exploring Cultural Perspectives in Education (pp. 349-365). Edmonton (Canada): ICRN Press.

Kotopoulos, H. T. (2006). Thessaloniki portrayed in the work of local novelists. Thessaloniki: Code.

Lehan, R. (1998). The City in Literature: An Intellectual and Cultural History. Berkeley, University of California Press.

Markou, G. (1997a). Introduction in the Intercultural Education, Greek and international experience. Athens: Institution of Cultural Education, Athens University.

Markou, G. (1997b). Intercultural Education. Teachers' training. An alternative proposal. Athens: Institution of Cultural Education - Athens University.

Martinidis, P. (1990). Comics. Art and illustrations techniques. Thessaloniki, A.S.E..

Nikolajeva, M., \& Scott, C. (2001). How picturebooks Work. New York \& London: Carland Publishing.

Nodelman, R. (1988). Words about Pictures, the narrative art of children's book. London: The University of Georgia Press.

Norton, E. D. (2007). Through the Eyes of a Child: An Introduction to Children's Literature. Translation Fotini Kaptsiki - Kazantzi Sevasti. Athens: Epikentro.

Oikonomou, A. I. (1992). Introduction in the Comparative Stereotypology of the national characteristics in Literature. Thessaloniki: University Press.

Pageaux, D. H. (1988). Image/imaginaire. In Dyserinck, H., \& Syndram, K. U. (Eds.), Europe and national Consciousness. Bonn.

Pike, B. (1981). The image of the city in modern literature. Princeton, New Jersey, Princeton University Press.

Raymond, W. (1973). The Country and the City. New York: Oxford University Press.

Sivropoulou, R. (2004). A journey to the world of the illustrative short stories. Athens: Metechmio.

Schönpflug, U. and Silbereisen, K. R. (1986). Ethnic Minorities. In Frick, D., \& Hoefert, H. W. (Eds.), The Quality of Urban Life. Social, Psychological, and Physical Conditions. Berlin \& New York: De Gruyter.

Schwartzman, H. B. (1979). Transformations: The Anthropology of Children's Play. New York: Plenum Press.

Sutton Smith, B. (1986). Toys as culture. New York: Gardner Press.

Tziovas, D. (1987). After the Esthetics. Athens: Knowledge.

Wirth - Nesher, H. (1996). City Codes. Cambridge: Cambridge University Press.

Note

Note 1. The number reports to corresponding numeration of each book (Appendix).

\section{Appendix}

1. Artzanidou, E. (2006). My name is Promise (illustration Grivas, V.). Athens, Psichogios.

2. Varela, A. (2004). Give the Love (illustration Alexandrou, M.). Athens, Patakis.

3. Papagianni, M. (2005). Three palm spreads the earth all around (illustration Karageorgiou, A.). Athens, Patakis. 
4. Nikoloudi, F. (2006). Good morning friend (illustration Skordi, F.). Athens, Ellinika Grammata.

5. Mantouvalou, S. (2002). Riko Kokoriko (illustration Solou T.). Athens, Militos.

6. karagianni, M. (2004). Blushy the red star (illustration Pepona, M.). Athens, Diaplasi.

7.Crhistidi, L. (2002). The White and Dark Chocolate (illustration Spathopoulou, E.). Athens, Anemomylos.

8. Matsuka, V. (2001). The flower called Harlekin (illustration Pepona, M.). Athens, Portokali.

9. Andrikopoulos, N. (2006). The country with the strange people (text and illustration Andrikopoulos, N.). Athens, Kalentis.

10. Skordala \& Kakatsaki, E. (2004). The Happy and the rainbow (illustration Denezaki, L.). Athens, Kaleidoscope.

11. Haravas, K. (2004). Black sky with pink clouds (illustration Tsafadaki, M.). Athens, Patakis.

12. Giannikou, K. (2004). Fatou the little girl from Senegal (Africa) (text and illustration Giannikou, K.). Athens, Modern Times.

13. Stamati, A. (2004). Hello, my little island! (text and illustration Stamati, A.). Athens, Kastor.

14. Varvarousi, L. (2006). A worm with.... wings (text and illustration Varvarousi, L.). Athens, Papadopoulos.

15. Iliopoulos, V. (1999). The triangular little fish (illustration Varvarous, L.). Athens, Patakis.

16. Mastori, V. (2002). My magical ears (illustration Gousis, S.). Athens, Patakis.

17. Mara, I. (2000). The little Doop, (Irene, illustration Spathopoulou, E.). Athens, Patakis.

18. Savouaza, E. (2001). The dwarf and the little shrimp (illustration Rembena, F., translated by Karakitsios, A.). Athens, Sinhroni Orizontes.

19. Stathatou, F. (1991). "Thomas" / Five circles in search of color. Athens, Angira.

20. Grekou, G. (2004). Phoebus... and the other Phoebus (illustration Simeonidi, A.). Athens, Ellinika Grammata.

21. Aftzis, M. (2004). I just want to you to play with me (illustration Adrikopoulos, N.). Athens, Ellinika Grammata.

22. Fitzimoris, M. (2004). Sakis the Centipede (illustration Kitamoura, S., translated by Tourkolia \& Kydoneos, R.). Athens, Patakis. 